\title{
Recirculating aquaculture systems waste water as a medium for increase of phytoplankton and zooplankton biomass
}

\section{Oleksii Khudyi $^{\mathrm{a} *}$, Mykhailo Marchenko ${ }^{\mathrm{b}}$, Larysa Cheban ${ }^{\mathrm{c}}$, Lidiia Khuda ${ }^{\mathrm{d}}$, Olga Kushniryk ${ }^{e}$ and Iryna Malishchuk ${ }^{f}$}

Yuriy Fedkovych Chernivtsi National University, 2 Kotsjubynskyi St., Chernivtsi 58012, Ukraine

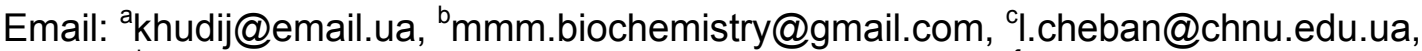 \\ didiia_khuda@email.ua, ${ }^{\mathrm{e}}$ kushniryk-olga@email.ua, fumwelt@ukr.net
}

\begin{abstract}
Keywords: live feed for fish, waste water, RAS, cultivation, phytoplankton, nutritional value,
\end{abstract} zooplankton.

\begin{abstract}
The results of using the waste water from recirculating aquaculture system for phytoand zooplankton cultivation are presented in the article. The physico-chemical parameters of the aquaculture system's waste water and comparative culture media were recorded during hydrobionts cultivation. The indicators of productivity and the biochemical composition of investigated cultures were determined. The biochemical analysis of studied cultures included the investigations of the content of total proteins, lipids, carbohydrates, carotenoids and photosynthetic pigments. Using aquaculture system's waste water as a medium for the cultivation of phyto- and zooplankton can significantly reduce the cost of technology for live feed biomass increase in the aquaculture industries.
\end{abstract}

\section{INTRODUCTION}

Conventional methods of biotechnology for phyto- and zooplankton cultivation involve artificial cultivation media presented by sets of macro- and microelement salts $[1,2]$. The reduce of technological costs during cultivation of live feed for young fish can be achieved by utilizing an alternative medium that provides the advantage of being financially and economically efficient. To maintain proper water quality in Recirculating aquaculture system (RAS), some water must be added periodically to replace evaporative loses and that used to flush out waste materials [3]. Aquaculture waste water effluents can be used as an inexpensive alternative to the traditional media for hydrobionts cultivation. Our previous studies have confirmed the principal possibility of using the RAS waste water as a medium for phytoplankton and zooplankton cultivation $[4,5]$.

\section{MATERIALS AND METHODS}

Research objects. The study was performed on the pure cultures of green algae Desmodesmus armatus (Chod.) Chod. (IBASU-A), Acutodesmus dimorphus (Turpin) Tsarenko (IBASU-A) and blue-green algae Anabaena hassalii (Kutz.) Wittr. (NRDR), Nostoc linckia Roth. (HPDP) from the collections of the Institute of Hydrobiology of NAS of Ukraine (HPDP) and M.G. Kholodny Institute of Botany of NAS of Ukraine (IBASU-A) and on the monocultures of cladocerans Moina macrocopa (Straus, 1820) and Simocephalus vetulus (Müller, 1776) that are in the collection of the Institute of Biology, Chemistry and Bioresourses of Yuriy Fedkovych Chernivtsi National University.

Cultivation conditions. The cultivation of the organisms of interest was carried out in a climatic chamber at a temperature of $21 \pm 2{ }^{\circ} \mathrm{C}$, illuminated with 2500 lux fluorescent lamps for a 16-hour photoperiod [6].

The waste water was obtained from a mechanical filter of the RAS, which operates at the Institute of Biology, Chemistry and Bioresourses of Yuriy Fedkovych Chernivtsi National University. The physicochemical parameters of the culture media were monitored throughout phyto- and zooplankton cultivation. The $\mathrm{pH}$ and redox-potential levels were recorded using an I-160 
MI ion meter with appropriate selective electrodes. Conductivity and total mineralization in the culture media was determined with a Water Quality Tester COM-100 conductivity meter. The control of the dissolved oxygen was carried out by potentiometric method using a PDO-607 oxygen meter. The determination of mineral content in the waste water from the RAS was conducted in accordance with conventional methods [7].

For phytoplankton cultivation the waste water poured in aliquots was placed in the heat-resistant containers with the ground stoppers. The samples distributed by volume were then autoclaved at $121 \pm 2^{\circ} \mathrm{C}$ for $30 \pm 5$ minutes in a steam sterilizer. After sterilization the water was cooled to room temperature. Fitzgerald's medium No 11 with Zehnder's and Gorham's modifications [2] was used as the comparative medium. The phytoplankton cultures were seeded into the chilled sterile water and Fitzgerald's medium at a ratio of inoculum : culture medium of 1:10 under laminar-boxing conditions. The containers were placed to the climate chamber for biomass increasing for the period of 40 days. Biomass was determined spectrophotometrically by culture density at the wavelength of $750 \mathrm{~nm}$. The transition from units of optical density $\left(D_{750}\right)$ to the value of absolutely dry biomass (ADB) was done with empirical coefficient k (Eq. 1):

$$
\mathrm{ADB}=\mathrm{k} \times \mathrm{D}_{750}
$$

Coefficient $\mathrm{k}$ for each of the cultures was determined experimentally in three independent replicates (Eq. 2):

$$
k=\mathrm{g} \times \text { absorbance units } \times 1^{-1}
$$

The cultivation of the zooplankton was carried out during the period of 24 days in the $0.5 \mathrm{~L}$ volumes with the initial number of 50 individuals per liter. Aqueous suspension of the yeasts Saccharomyces cerevisiae was used as a feed substrate for the zooplankton $[8,9]$. Yeasts with the number of cells adjusted to $23,5-24,5 \times 10^{6} \mathrm{CFU}$ per 1 liter of medium were applied every 48 hours. In the experimental groups the cultures of $S$. vetulus and $M$. macrocopa were grown on the waste water that was obtained from a RAS mechanical filter and utilized without additional filtration and sterilization. Organisms of $S$. vetulus and M. macrocopa cultivated in a synthetic ADaM medium were used as the control [1]. The crustaceans were counted using the aliquot method with a Bogorov camera under a MicroMed XS-3300 binocular microscope.

Preparation for biochemical analysis. The sampling for biochemical analysis was carried out in the phase of maximum productivity. The concentrated samples of algae and zooplankton were treated with a USDN-2T ultrasonic desintegrator. Homogenization of the test material was performed at $+4{ }^{\circ} \mathrm{C}$ using buffers: Tris/phosphate buffer $\mathrm{pH} 7.5$ for phytoplankton and phosphate buffer $\mathrm{pH} 7.4$ for zooplankton. The homogenate was centrifuged at $1500 \mathrm{~g}$ per 15 min with Biofuge Stratos (Heraeus Instruments).

Biochemical analysis. The content of main nutrients was defined in the studied samples. Total lipids extracted with Folch method [10] were determined after acid hydrolysis of the samples with the subsequent reaction between decomposition products and the phospho-vanillin reagent [11]. Total protein content was defined by Lowry method [12]. The content of carbohydrates was determined by a color reaction with the anthrone reagent [13]. Additionally, the content of chlorophyll $a, b$ [14], and total carotenoids [15] were determined in algae cells. The pigments were extracted from microalgae cells with absolute acetone. The spectra of the pigment extracts were measured by spectrophotometry in the wavelength range of 400-800 $\mathrm{nm}$. The calculations of pigment concentrations were conducted according to optical density indexes [16] at wavelengths corresponding to maxima absorption of chlorophyll $a, b$, and total carotenoids.

All calculations were performed on dry weights. To determine humidity and dry weights, previously weighed samples were dried at $60^{\circ} \mathrm{C}$ for 24 hours to constant mass [17]. 
Statistical analysis. The results were analyzed statistically with Microsoft Excel software and Single Factor ANOVA Tukey HSD test, STATISTICA 6.0 application package, according to generally accepted methods [18]. Mean values were considered significantly different at $\mathrm{P} \leq 0,05$ according to Student's criterion.

\section{RESULTS AND DISCUSSION}

Physico-chemical parameters of RAS post-production water in comparison with standardized culture media. In accordance to the research results, the basic physicochemical characteristics of the RAS waste water definitively correspond to Fitzgerald's medium for microalgae cultivation (Table 1).

Table 1. Physico-chemical parameters of different types culture media.

\begin{tabular}{|l|c|c|c|}
\hline \multicolumn{1}{|c|}{ Characteristics of culture media } & RAS waste water & Fitzgerald's medium & ADaM \\
\hline Total mineralization $[\mathrm{mg} / \mathrm{L}]$ & $371,0-477,0$ & $232,0-547,0$ & $759,0-1023,0$ \\
\hline Conductivity $[\mu \mathrm{S} / \mathrm{mL}]$ & $555,0-693,0$ & $452,0-690,0$ & $1080,0-1497,0$ \\
\hline $\mathrm{pH}$ & $7,0-8,0$ & $7,0-8,0$ & $7,9-8,2$ \\
\hline Redox potential $[\mathrm{mV}]$ & $211,4-213,9$ & $176,9-245,0$ & $191,9-229,2$ \\
\hline
\end{tabular}

A significant amount of biogenic elements enters the water with feed and is excreted by fish [19]. Besides, the intensive methods of RAS fish culture require the feeds that provide mineral and nutritional supplementation sufficient to meet the fish's requirements; however, some quantities of nutrients and minerals are leached from the feed into the surrounding water. Since RASs hold fish in high density, the concentration of biogenes and trace elements in waste waters that come from the fish-breeding reservoirs to the purification unit can be quite high. Obviously, the presence of soluble forms of nitrogen, phosphates and microelement salts should favorably influence the algae development. On the other hand the concentration of nitrogen soluble forms $\left(\mathrm{NH}_{4}^{+}, \mathrm{NO}_{2}^{-}, \mathrm{NO}_{3}{ }^{-}\right)$ and phosphates in the waste water, while not optimal for the cladocerans development, does not reach values that are critical for them.

Thus, it is assumed, that RAS waste water can potentiate phytoplankton growth and does not suppress the development of zooplankton, which in turn can ensure additional yield of biomass and reduce the costs of live feed cultivation.

Assessment of the efficiency of microalgae cultivation on RAS waste water. It is known that the productivity of a culture can vary considerably depending on the cultivation medium composition. The biomass of the microalgae cultures under study changed depending on the duration of cultivation and reached the maximum in the stationary phase both on the RAS waste water and the comparative medium (Fig. 1).

In the first days of cultivation on the RAS waste water low growth activity of all cultures was noted, which is obviously caused by the microalgae adapting to new conditions. High growth activity in the exponential phase of the microalgae growth on both studied media was due to a sufficient quantity of the available components of mineral nutrition. The optimal duration of cultivation is established that lasts for 40 days, after which the cultures begin entering the degradation phase. Their growth is limited by decreases in available nutrients and the accumulation of metabolic products in the culture fluid. This tendency is typical of all investigated species cultivated both on the RAS waste water and the comparative medium. 


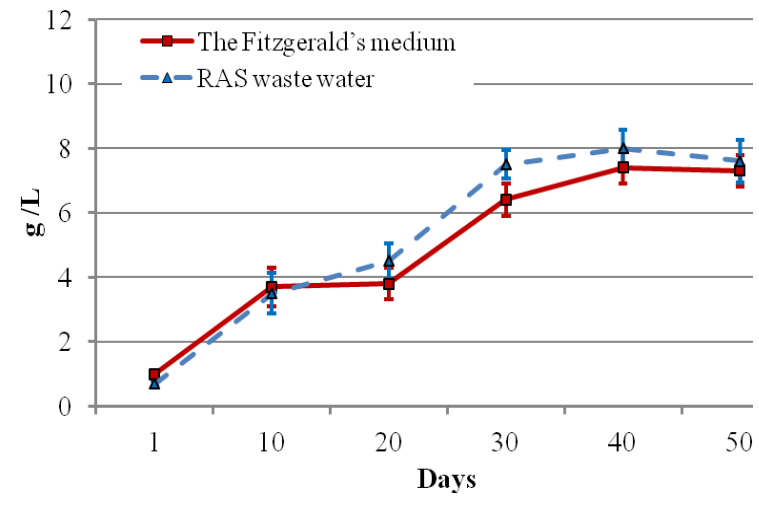

A. hassalii

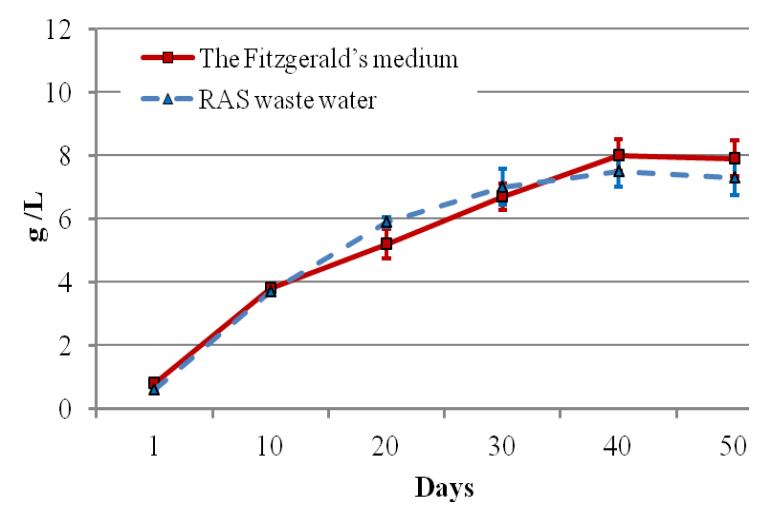

A. dimorphus

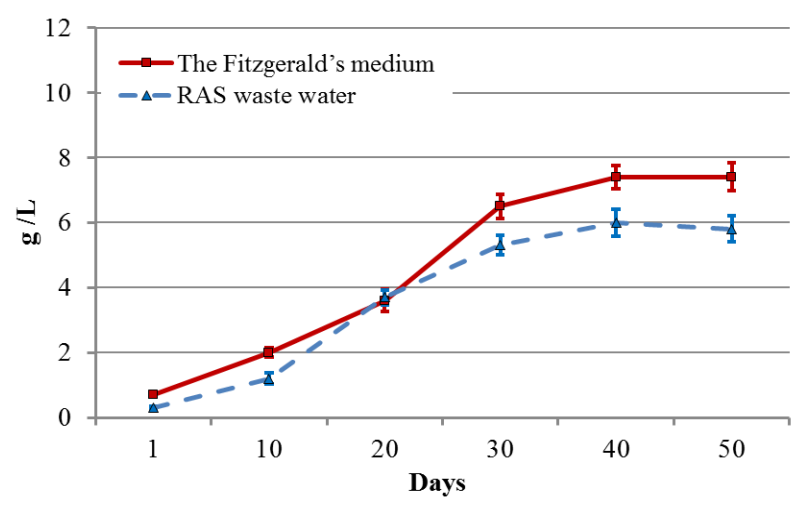

N. linckia

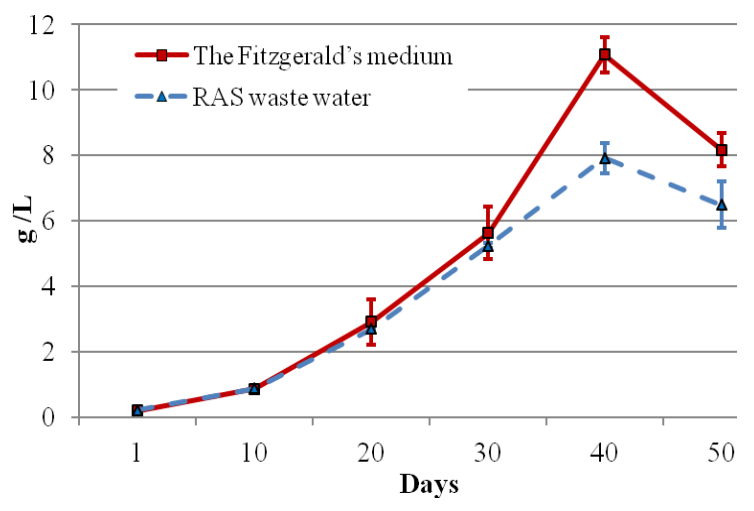

D. armatus

Fig. 1. The biomass of the microalgae cultures during cultivation on the waste water and on the comparative medium

The processes of nutrients accumulation, including proteins, lipids, carbohydrates and pigments, were activated during active biomass increase. The maximal values of protein content in the studied cultures with the use of the waste water as a culture medium were between 55 and $64 \%$ of the dry weight (Table 2). For the control medium, this parameter is little higher.

Table 2 . The productivity parameters of investigated microalgae cultures.

\begin{tabular}{|c|c|c|c|c|c|c|}
\hline & \multicolumn{2}{|c|}{ Total proteins [\%] } & \multicolumn{2}{|c|}{ Total lipids [\%] } & \multicolumn{2}{|c|}{ Carbohydrates [\%] } \\
\hline & $\begin{array}{l}\text { Fitzgerald's } \\
\text { medium }\end{array}$ & Waste water & $\begin{array}{l}\text { Fitzgerald's } \\
\text { medium }\end{array}$ & Waste water & $\begin{array}{l}\text { Fitzgerald's } \\
\text { medium }\end{array}$ & Waste water \\
\hline S. armatus & $63,9 \pm 2,67$ & $60,1 \pm 2,34$ & $14,9 \pm 1,14$ & $14,8 \pm 1,14$ & $11,7 \pm 1,18$ & $11,6 \pm 1,05$ \\
\hline A. dimorphus & $60,1 \pm 2,80$ & $59,7 \pm 2,39$ & $14,7 \pm 1,20$ & $14,1 \pm 1,29$ & $11,7 \pm 1,13$ & $11,5 \pm 1,25$ \\
\hline A. hassalii & $58,8 \pm 2,49$ & $58,0 \pm 2,18$ & $15,4 \pm 1,05$ & $15,3 \pm 1,12$ & $10,9 \pm 1,25$ & $11,2 \pm 1,15$ \\
\hline \multirow[t]{3}{*}{ N. linckia } & $56,6 \pm 2,82$ & $55,1 \pm 2,97$ & $15,6 \pm 1,14$ & $15,0 \pm 1,14$ & $11,5 \pm 1,06$ & $11,7 \pm 1,07$ \\
\hline & \multicolumn{2}{|c|}{ Chlorophyll $a[\mathrm{mg} / \mathrm{g}]$} & \multicolumn{2}{|c|}{ Chlorophyll $b[\mathrm{mg} / \mathrm{g}]$} & \multicolumn{2}{|c|}{ Carotenoids $[\mathrm{mg} / \mathrm{g}]$} \\
\hline & $\begin{array}{l}\text { Fitzgerald's } \\
\text { medium }\end{array}$ & Waste water & $\begin{array}{l}\text { Fitzgerald's } \\
\text { medium }\end{array}$ & Waste water & $\begin{array}{l}\text { Fitzgerald's } \\
\text { medium }\end{array}$ & Waste water \\
\hline S.armatus & $19,1 \pm 1,20$ & $18,7 \pm 1,21$ & $7,5 \pm 0,89$ & $7,1 \pm 0,65$ & $14,4 \pm 0,71$ & $13,5 \pm 0,93$ \\
\hline A.dimorphus & $20,9 \pm 1,76$ & $19,9 \pm 1,20$ & $7,7 \pm 0,80$ & $7,0 \pm 0,69$ & $14,2 \pm 0,81$ & $13,3 \pm 0,83$ \\
\hline A.hassalii & $17,8 \pm 1,06$ & $15,4 \pm 1,52$ & - & - & $18,0 \pm 0,99$ & $15,7 \pm 0,75$ \\
\hline N.linckia & $19,1 \pm 1,31$ & $16,9 \pm 1,18$ & - & - & $18,5 \pm 0,92$ & $15,6 \pm 0,73$ \\
\hline
\end{tabular}

This regularity was also noted when studying the quantitative content of lipids and carbohydrates during the cultivation on both culture media. There were no significant differences in the qualitative content of these compounds in all species.

A gradual increase in the amounts of chlorophyll $a, b$ (for green algae) and carotenoids was noted, and they reached maximum values at the stationary phase of culture growth. The amount of 
algae pigments depended on the features of accumulative cultivation and on the content of culture medium. It is another indicator of algae culture productivity since the dependence of photosynthetic efficiency on the mineral nutrients is determined by their necessity both in the formation of the photosynthetic apparatus and its renewal during the lifetime of the culture.

So, during long-term cultivation, the increasing of cell numbers leads to the exhaustion of the culture medium and shortages of certain minerals. At the same time, microalgae cultures are shaded by their own high densities, which gradually leads to the features of pigments accumulation in both culture media that were established previously.

Obtained values do not differ significantly from the control indicators, and the cultivation conditions and waste water composition are sufficient for high productivity of the cultures and do not carry stress load on the cultures under study. The cultivation of these algological pure cultures on waste water is an inexpensive and promising source of feed or premixes for zooplankton cultivation.

Assessment of the efficiency of zooplankton cultivation on the RAS waste water. RAS waste water can be used as a culture medium for the intensive development of zooplankton. An increase of organisms density and, respectively, the biomass of the cultures lasts up to day 18 of cultivation, when it reaches maximum values (Fig. 2). The most intensive growth of the organisms, cultivated in ADaM medium, was observed between the second and the fourth day of the experiment, and upon further cultivation a gradual decrease was noted until the complete loss of the cultures of both Cladocera species under study on day 14 of cultivation. Thus, using RAS waste water for cultivating crustaceans not only delays the growth slowdown, but also significantly increases density and biomass of both zooplankton monocultures under analysis.

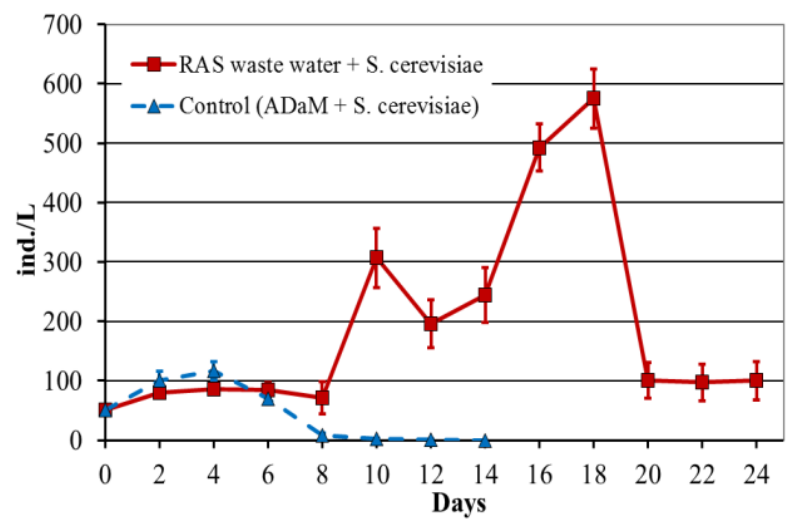

S. vetulus

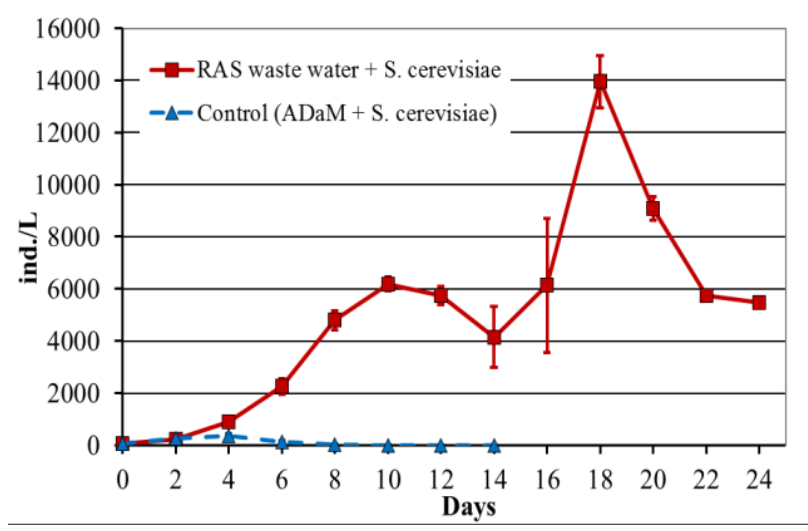

M. macrocopa

Fig. 2. Density dynamics of zooplankton cultures during cultivation on different media

An increase in the density of zooplankton monocultures during their cultivation on RAS waste water could represent the bacterial flora in this water, that serves an additional feed element for crustaceans and contributes to their reproduction [20].

When cultured on a synthetic medium, no significant differences were observed in the growth rate between Moina and Simocephalus. Despite similar trends in the growth dynamics, the culture of M. macrocopa responds much better to the replacement of the cultivation medium, than $S$. vetulus monoculture. Thus, on the density peak of both cultures the number of Moina individuals was about 23 times higher compared to Simocephalus.

The studied organisms react differently to the replacement of the cultivation medium. So, the content of total proteins in $S$. vetulus monoculture that was cultivated in waste water was almost $20 \%$ higher in comparison to the culture grown in the artificial medium, while total proteins and lipids in $M$. macrocopa that was cultivated in both culture media do not substantially differ in qualitative composition. (Table 3). 
Table 3. The indicators of productivity and nutritional value of $S$. vetulus and M. macrocopa cultures while cultivating on different media.

\begin{tabular}{|l|l|c|c|c|c|}
\hline \multicolumn{2}{|c|}{ Type of medium } & $\begin{array}{c}\text { Maximal density } \\
{[\text { ind./L] }}\end{array}$ & $\begin{array}{c}\text { Maximal } \\
\text { biomass [g/L] }\end{array}$ & $\begin{array}{c}\text { Total proteins } \\
{[\mathrm{mg} / \mathrm{L}]}\end{array}$ & $\begin{array}{c}\text { Total lipids } \\
{[\mathrm{mg} / \mathrm{L}]}\end{array}$ \\
\hline \multirow{3}{*}{ S. vetulus } & RAS waste water & $575 \pm 44^{*}$ & $0,09 \pm 0,030^{*}$ & $623,1 \pm 58,5^{*}$ & $163,9 \pm 10,9$ \\
\cline { 2 - 6 } & ADaM & $120 \pm 7$ & $0,02 \pm 0,004$ & $501,7 \pm 43,8$ & $179,3 \pm 5,3$ \\
\hline \multirow{2}{*}{ M. macrocopa } & RAS waste water & $13950 \pm 1000^{*}$ & $0,91 \pm 0,152^{*}$ & $606 \pm 54,7$ & $118 \pm 10,0$ \\
\cline { 2 - 6 } & ADaM & $365 \pm 69$ & $0,02 \pm 0,003$ & $630 \pm 75,3$ & $107 \pm 29,7$ \\
\hline
\end{tabular}

* differences between groups are statistically significant: $\mathrm{P} \leq 0,05$.

Thus, using RAS waste water as a culture medium in S. vetulus and M. macrocopa cultivation does not result in the degraded zooplankton nutritional value.

\section{CONCLUSIONS}

1. Qualitative characteristics of RAS waste water allow its use for the cultivation of phyto- and zooplankton. The fish-breeding RAS waste water does not decrease productivity of the algacultures under analysis and provides a significant improvement in the growth dynamics of zooplankton cultures compared to the artificial cultivation media.

2. Using RAS waste water does not result in the degraded nutritional value of the organisms under sudy.

3. Using RAS waste water as a medium for the cultivation of phyto- and zooplankton can significantly reduce the cost of technology for live feed biomass increase in the aquaculture industries.

\section{References}

[1] B. Kluttgen, U. Dulmer, M. Engels, H.T. Ratte, ADaM, an artificial freshwater for the culture of zooplankton. Water Res. 28 (1994) 743-746.

[2] E.K. Zolotaryova, E.I. Shnyukova, O.O. Syvash, N.Ph. Mykhailenko, The prospects of microalgae use in biotechnology, Altpress, Kyiv, 2008.

[3] Michael B. Timmons, James M. Ebeling, Recirculating Aquaculture, NRAC Publication No 01-007, Cayuga Aqua Ventures, Ithaca, NY, 2007.

[4] O. Kushniryk, O. Khudyi, L. Khuda, R. Kolman, M. Marchenko, Cultivating Moina macrocopa Straus in different media using carotenogenic yeast Rhodotorula, Arch. Pol. Fish. 23 (2015) 37-42.

[5] L.M. Cheban, I.V. Malischuk, M.M. Marchenko, Cultivating Desmodesmus armatus (Chod.) Hegew. in recirculating aquaculture systems (RAS) waste water, Arch. Pol. Fish. 23 (2015) 155-162.

[6] V.D. Romanenko, Yu. G. Krot, L.A. Syrenko, V.D. Solomatina, The biotechnology of hydrobionts cultivation, Institute of Hydrobiology of NAS of Ukraine, Kyiv, 1999.

[7] O.M. Arsan, O.A. Davydov, T.M. Dyachenko, M.Yu. Yevtushenko, V.M. Zhukynskyy, The methods of hydroecological investigations of surface waters, Logos, Kyiv, 2006.

[8] K. Chakri, H. Berrak, B. Samraoui, Effect of food concentration on the development, growth, reproduction and total life span of Simocephalus expinosus Koch (Cladocera: Daphniidae), Annals of Biological Research, 5 (1) (2014) 55-58.

[9] B. Khatun, R. Rahman, M.S. Rahman, Evaluation of yeast Saccharomyces cerevisiae and algae Chlorella vulgaris as diet for rotifer Brachionus calyciflorus, The Agriculturists, 12 (1) (2014) 1-9. 
[10] J. Folch, M. Lees, G.H.S. Stanley, A simple method for the isolation and purification of total lipides from animal tissues, J. Biol. Chem. 226 (1957) 497-509.

[11] J.A. Knight, S. Anderson, J.M. Rawle, Chemical basis of the sulfo-phospho-vanillin. Reaction for estimating total serum lipid, Clinical Chemistry18 (1972) 199-202.

[12] O.H. Lowry, N.J. Rosebrough, A.L. Farr, R.J. Randall, Protein measurement with the Folin phenol reagent, J. Biol. Chem. 193 (1951) 265-275.

[13] S.H. Roe, The determination of sugar in blood and spinal fluid with anthrone reagent, J. BioI. Chem. 212 (1955) 334-343.

[14] D.N. Campbell, V.H. Hurry, A.K. Clarke, Chlorophyll fluorescence analysis of cyanobacterial photosynthesis and acclimation, Microbiol. Mol. Biol. Rev. 62 (1998) 667-683.

[15] M. Sanchez, C. Mantell Serrano, M. Rodriguez Rodriguez, E. Martinez de la Ossa, L. Lubian, O. Montero, Extraction of carotenoids and chlorophyll from microalgae with supercritical carbon dioxide and ethanol as cosolvent, J. Sep. Sci. 31 (2008) 1352-1362.

[16] S.W. Geffrey, G.F. Humphrey, New spectrophotometric equations for determining chlorophylls $\mathrm{a}, \mathrm{b}, \mathrm{c}_{1}$ and $\mathrm{c}_{2}$ in higher plants, algae and natural populations, Biochem. Physiol. Pflanzen. 167 (1975) 191-194.

[17] R.P. Harris, P.H. Wiebe, J. Lenz, H.R. Skjoldal, M. Huntley, Zooplankton methodology manual, Academic Press, London, 2000.

[18] A.A. Khalafyan, STATISTICA 6. Statistical analysis of data, third ed., Binom Press, Moscow, 2007.

[19] A. Giani, Implications of phytoplankton chemical composition for zooplankton production: experimental evidence, Oecologia, 87 (1991) 409-416.

[20] M.P. Sison-Mangus, A.A. Mushegian, D. Ebert, Water fleas require microbiota for survival, growth and reproduction, The ISME Journal, 9 (2015) 59-67. 